\title{
СЕМАНТИКА ТЕРМИНОВ ФОНЕТИКИ, ОБОЗНАЧАЮЩИХ ЕДИНИЦУ ИНТОНАЦИИ В АНГЛИЙСКОМ И РУССКОМ ЯЗЫКАХ
}

\section{THE SEMANTICS OF PHONETIC TERMS DENOTING UNITS OF INTONATION IN ENGLISH AND RUSSIAN}

\section{E. Matveeva}

Summary: The article deals with the semantic structure correlation of the phonetic terms denoting the basic unit of intonation. The analysis of definitions in specilialised English dictionaries revealed synonymous terms 'intonational phrase, 'tone unit', 'tone group', 'intonation group'. By means of comparing their functional characteristics and frequency of occurrence obsolete terms as well as lexical units most commonly used nowadays have been identified. The synonyms in question have been contrasted with the meanings of Russian terms «синтагма» and "фраза», which allowed to determine that the Russian term "фраза» is equivalent to the English special lexemes denoting the basic unit of intonation structure.

Keywords: term, phonetic term, semantics, intonation, intonational phrase.

\author{
Матвеева Евгения Евгеньевна \\ К.филол.н., дочент, ГАОУ ВО «Московский городской \\ педагогический университет», г. Москва \\ Jenny3574@yandex.ru
}

Аннотация: В статье рассматривается проблема соотношения семантических структур терминов фонетики, служащих для обозначения основной единицы интонации. Анализ словарных статей специальных словарей в английском языке позволил выявить синонимичные лексемы 'intonational phrase, 'tone unit,',tone group', 'intonation group.' На основе сравнения частотных характеристик функционирования указанных лексем были выявлены устаревшие термины и специальные единицы, являющиеся наиболее употребительными на современном этапе. Сопоставительный анализ значения исследуемых лексем-синонимов в английском языке и русскоязычных терминов «синтагма» и «фраза» позволил сделать вывод о совпадении семантических структур англоязычных терминов, обозначающих единицу интонации, и русскоязычной лексемы «фраза».

Ключевые слова: термин, термин фонетики, семантическая структура, интонация, фраза.

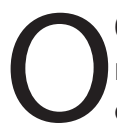

бщение специалистов в рамках определенных научных областей предполагает использование специальной лексики, отвечающей всем требованиям, предъявляемым к такого рода единицам, и обеспечивающей точность и однозначность передаваемой и получаемой информации. В связи с этим чрезвычайно актуальным видится изучение значения терминов фонетики, служащих для обозначения основных единиц интонации. Более того, такое исследование является перспективным и в русле межязыкового общения в данной специальной области.

Изучение терминологических единиц, а именно их семантической структуры, имеет своей целью не только упорядочение специальной лексики, обслуживающей фонетическую сторону речи, но и упрощение общения специалистов в данной сфере и устранение возможных трудностей и недопониманий как в рамках национальной, так и межнациональной профессиональной коммуникации.

Как известно, специальная лексика, включает в себя все лексические средства, так или иначе связанные с профессиональной деятельностью человека [7, с. 26]. На основе отображения словом определенного фрагмента действительности можно утверждать, что слово - двусторонняя единица, отражающая взаимозависимость значения и понятия об отображаемом объекте [2, с. 76].

По определению В.М. Лейчика, «термин - лексическая единица определенного языка для специальных целей, обозначающее общее - конкретное или абстрактное - понятие теории определенной специальной области знаний или деятельности» [5, с. 31-32].

Подобно тому как слово обладает звуковой оболочкой (план выражения) и внутренней структурой (план содержания) [2, с. 77], значение терминов как особых лексических единиц может быть изучено только в рамках определенной системы лексических единиц. При этом двойственность природы термина заключается в наличии плана выражения и плана содержания и не характеризуется единством [7, с. 85]. Таким образом, значение слова, а тем более термина, во многом зависит от общественно осознанных контекстов его употребления, т.е. является конвенциональным [2, с. 77].

Поскольку в качестве объекта терминологических исследований рассматривается терминология в целом, то и значение отдельных терминологических единиц следует изучать только сквозь призму совокупности специальных единиц, обслуживающих отдельную область знания [3, с. 70]. Как утверждают А.В. Суперанская, Н.В. Подольская и Н.В. Васильева, каждый язык членит 
действительность по-своему. В связи с этим значения отдельных слов - а соответственно и терминов как особых лексических единиц - и сферы их употребления не совпадают от языка к языку. Поэтому требуется соотнесение терминологической единицы со всей системой понятий определенной отрасли знания [8, с. 187].

По мысли С.В. Гринева-Гриневича, семантика термина представляет собой комплекс взаимодействующих между собой лексического и понятийного значений [4, с. 90]. Вследствие особого характера термина как единицы специального языка, призванного обслуживать определенную область знания, к его семантической структуре предъявляется ряд требований, среди которых выделяют однозначность, полнозначность, непротиворечивость семантики и отсутствие синонимов [4, с. 31].

Синонимия традиционно рассматривается как явление в семантике слова (термина), при котором для обозначения одного понятия используется две и более лексические единицы [5, с. 91]. По мнению А.В. Суперанской, Н.В. Подольской, Н.В. Васильевой, «синонимы - это знаки, максимально приближенные друг к другу вследствие сходства связанных с ними понятий и общности именуемых вещей» [7, с. 49]. При этом в общеупотребительном языке явление синонимии трактуется в положительном ключе, обогащая язык и помогая избежать повторов, в то время как в специальной лексике синонимия - скорее, отрицательный, хотя и неизбежный, фактор развития терминологии.

Специальная лексика, как известно, подвергается нормированию особого рода, в основе которого лежит производственная правильность, связанная с условиями соответствующего подъязыка [7, с. 28]. Устранение синонимии часто становится одной из целей гармонизации терминологии определенной области знания, поскольку существование условных синонимов (одноязычных терминов с подобным значением) и квазиэквивалентов (неполных эквивалентов в других языках) может представлять определенную трудность при общении специалистов [4, с. 105-108].

Наличие синонимов в терминологии может объясняться рядом причин, а именно:

- метадиалектами различных научных школ;

- идиолектами отдельных исследователей;

- варьированием формы термина;

- использованием в номинации различных аспектов одного объекта;

- заимствованием термина с последующим появлением семантического дублета в родном языке;

- одновременным заимствованием двух равнозначных терминов;

- существованием официального и разговорного вариантов;
- существованием современного и устаревшего терминов;

- существованием полного и краткого вариантов и др. [4, с. 102-103].

С целью определения особенностей значения терминов, обозначающих единицы интонации, необходимо проанализировать их дефиниции в англо-английских словарях - лексикографических источниках по лингвистике и специальных словарях фонетических терминов.

Так, в словаре Д. Кристала 'A Dictionary of Linguistics and Phonetics' 2008 г. значение 'syntagm(a)' рассматривается исключительно через определение синтагматики, т.е. линейной связи элементов в речи [9, р. 470-471]. При этом подчеркивается, что синтагматические отношения могут быть определены на всех уровнях языка, однако в отношении интонационной структуры языка рассматриваемая лексема не используется.

Кроме того, говоря об интонации, автор утверждает следующее:

intonation (n.) A term used in the study of suprasegmental phonology, referring to the distinctive use of patterns of pitch, or melody. <...>A formal category of intonational phrase is also sometimes recognized: an utterance span dominated by boundary tones [9, р. 252]. (Интонация - термин, который используется в суперсегментной фонологии и относится к использованию определенных моделей изменения тона, или мелодики. <...> Иногда еще выделяется категория intonational phrase (интонационной фразы) как отрезка высказывания, где главным элементом являются «пограничные» тоны. - пер. автора).

Однако, по мнению Р. Л. Траска, 'intonational phrase' (also intonation group, rhythm unit) - the phonological unit of intonational structure, the longest stretch of speech to which a single intonation pattern applies <...> [11, p. 184]. (Интонационная фраза - фонологическая единица интонационной структуры, самый длинный отрезок, который соотносится с интонационной моделью. - пер. автора). Как видно из определения, существует несколько синонимов данному термину, обозначающему мельчайшую единицу интонационной структуры языка, - 'intonation group','rhythm unit'.

Еще одним вариантом обозначения основной единицы интонации Д. Кристал называет 'tone unit/group':

tone unit $A$ term used by some intonation analysts, particularly those working within the British tradition, to refer to a distinctive sequence of pitches, or tones, in an utterance; also called a tone group. The essential feature of a tone unit is the nuclear tone, the most prominent tone in the sequence $<\ldots>$ [9, p. 487]. (- термин, который используется некоторыми интонологами, в особенности теми, 
кто работает в британской традиции, для обозначения особой последовательности тонов в высказывании. Неотъемлемой частью tone unit (интонационной единицы) является наличие ядерного тона, наиболее выделенного тона во фразе <...>. - пер. автора).

В работе Р.Л. Траска 'Dictionary of Phonetics and Phonology' (2005) термину 'tone group' дается сходная дефиниция:

tone group - the fundamental unit of intonation, the stretch of utterance to which a single intonational contour applies [11, p. 357]. (- фундаментальная единица интонации, отрезок высказывания, коррелирующий с одним интонационным контуром. - пер. автора).

При этом Д. Кристал отмечает, что 'tone unit' включает в себя 'pre-head' (предтакт), 'head' (такт, шкала) и 'tail' (затакт) [9, р. 487]. Аналогичную структуру данной единицы интонации 'tone unit' отмечает и П. Роуч в книге 'A Little Encyclopedia of Phonetics' 2002 г.: <...> while the approach most widely used in Britain takes the tone unit as its basic unit and looks at the different pitch possibilities of the various components of the tone unit (the pre-head, head, tonic syllable/nucleus and tail) [10, p. 39-40]. (-<..> в то время как подход, который используется в Британии рассматривает 'tone unit' (интонационную единицу) как основную единицу [интонации] и исследует тонические возможности ее компонентов (предтакта, шкалы, ядерного тона и затакта). - пер. автора).

Проведенный анализ словарный статей из специальных словарей в области фонетики позволил выявить несколько лексем, обозначающих единицы интонации intonational phrase, tone unit, tone group, intonation group, rhythm unit. Последний термин 'rhythm unit' является примером ложномотивирующей единицы, поскольку ориентирует читателя не на интонационные характеристики (движение тона, мелодику), а на особенности ритмической организации высказывания. В связи с этим дальнейшее рассмотрение данного термина в значении основной единицы интонации видится нецелесообразным. Очевидно, что наличие синонимии в данной области объясняется во многом метадиалектами различных научных школ (в частности, британской традиции) и идиолектами отдельных исследователей-фонетистов.

С целью выявления наиболее приемлемого термина, обозначающего основную единицу интонационной структуры английского языка, можно руководствоваться критериями употребительности и современности лексических единиц. С помощью инструмента Google Ngram Viewer были выявлены частотные характеристики терминов 'intonational phrase', 'tone unit', 'tone group', 'intonation group' в англоязычном корпусе текстов в период с 1900 г. по 2019 г. (см. рис. 1). Анализ полученных данных позволяет сделать вывод об определенных периодах повышенного интереса к интонологическим исследованиям, которые пришлись на 1980-1990-е гг. и 2000-е годы. На современном этапе наблюдается понижение интереса к изучению фонетической стороны речи, а именно исследованию интонационных структур, что наглядно продемонстрировано на рис. 1.

Как известно, два варианта английского языка - британский и американский - отличаются не только лексическими особенностями общеупотребительного языка, но и научными традициями, что отражается в терминосистемах определенных специальных областей. В связи с этим целесообразным видится исследование частотности употребления терминологических единиц, верба-

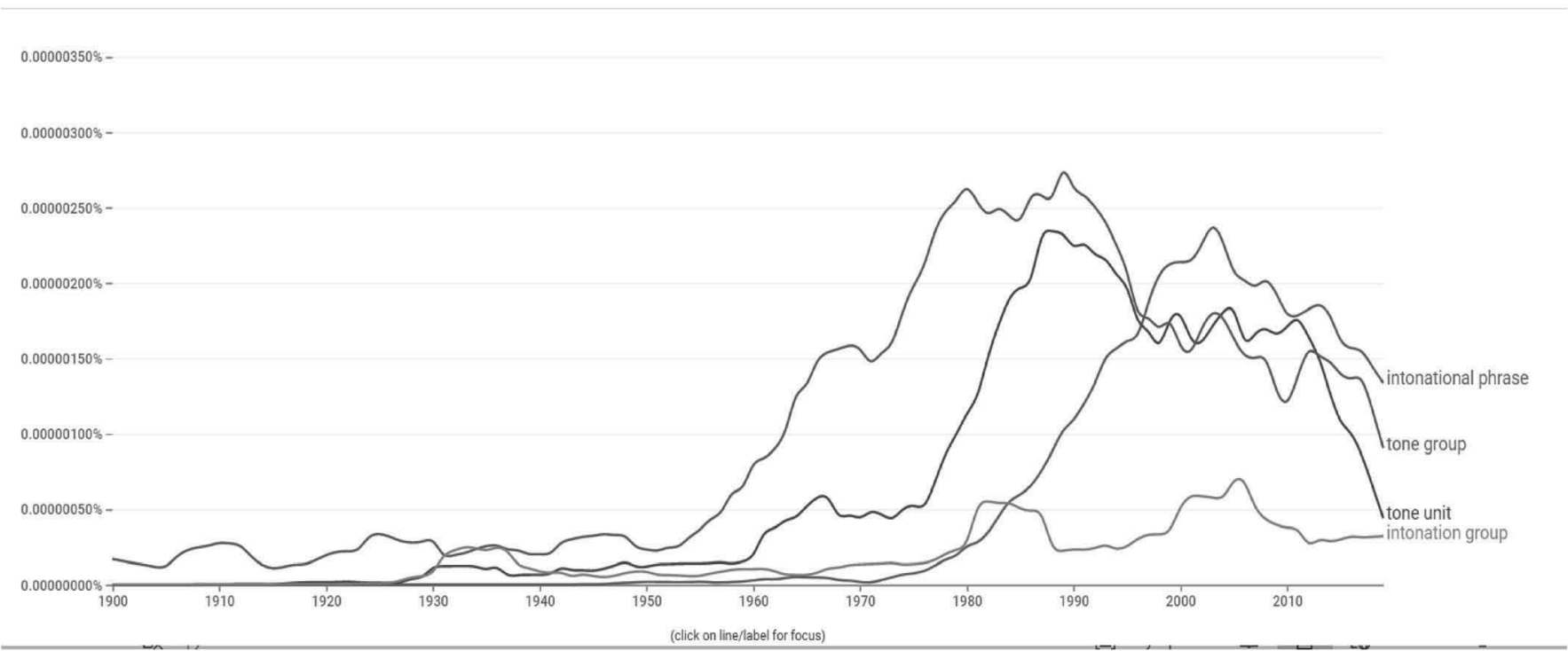

Рис. 1. Частотность использования терминов 'intonational phrase,' 'tone unit', 'tone group', 'intonation group' (Англоязычный корпус, 1900-2019 гг.) 


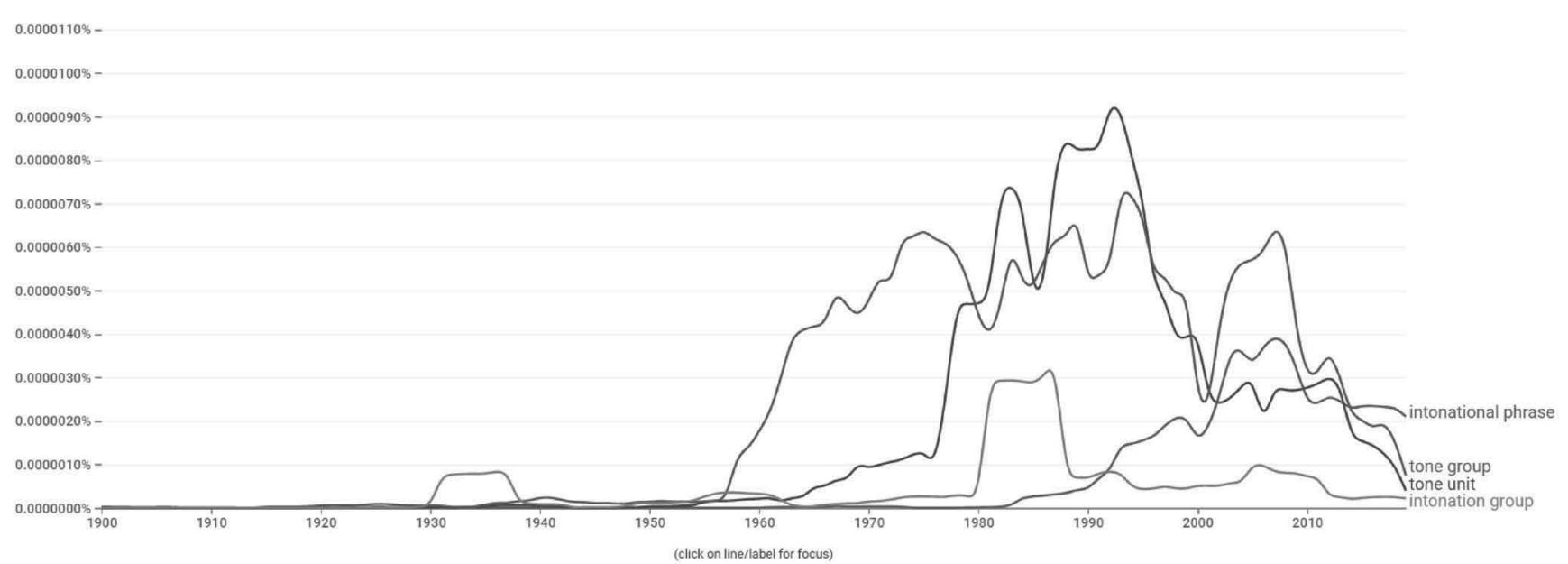

Рис. 2. Частотность использования терминов 'intonational phrase,' 'tone unit,' 'tone group', 'intonation group' (Британский корпус, 1900-2019 гг.)

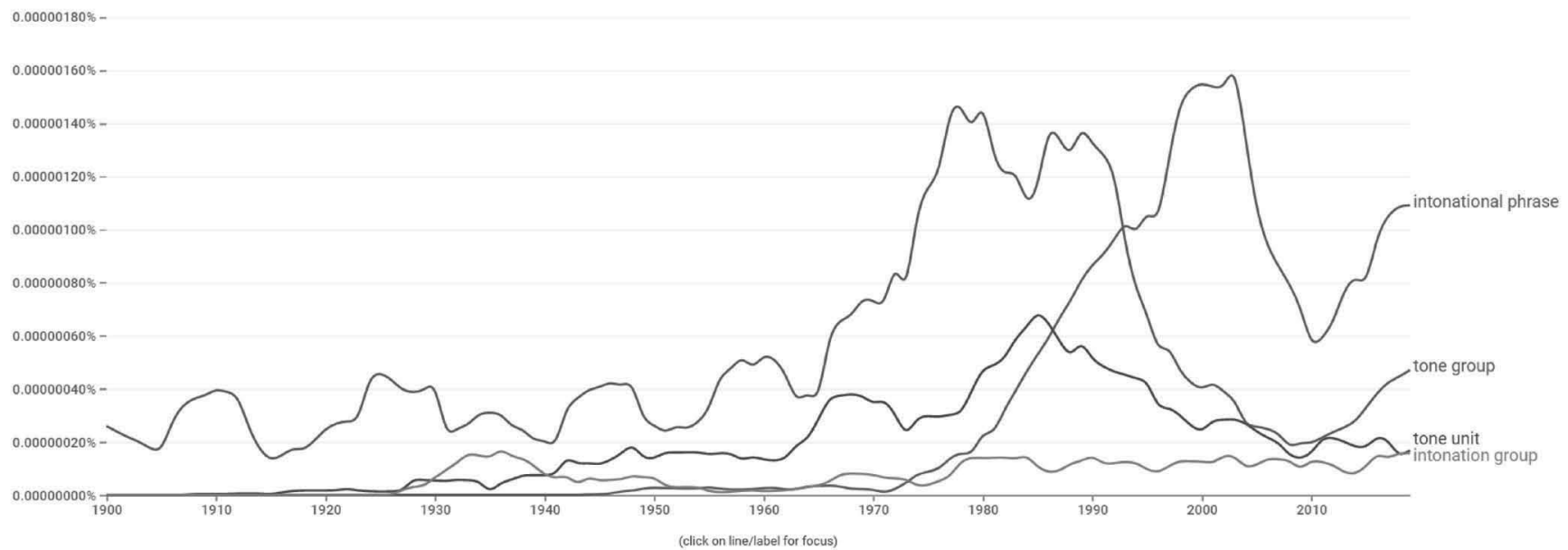

Рис. 3. Частотность использования терминов 'intonational phrase,' 'tone unit', 'tone group', 'intonation group' (Американский корпус, 1900-2019 гг.)

лизующих основную единицу интонации, в Британском и Американском корпусах текстов в период с 1900 г. по 2019 г. (см. рис. 2 и рис. 3)

Как видно из приведенного выше рис. 2, в британской традиции наибольшей употребительностью в 19801990-е гг. пользовались термины 'tone group' и 'tone unit', однако на современном этапе, начиная с 2000-х годов исследователи отдают предпочтение терминологической единице 'intonational phrase'. При этом термин 'intonation group' в современных исследованиях, посвященных интонационной структуре английского языка, практически не используется.

В Американском корпусе текстов наблюдается сходная картина, однако заметна тенденция к более частому использованию термина 'intonational phrase' по сравнению с текстами Британского корпуса (см. рис 3). Терминологическая единица 'tone group' также отличается большей частотностью в американской фонетической традиции.

Поскольку термины, служащие для обозначения основной единицы интонации, часто переводятся на русский язык как «интонационная группа» или «синтагма», необходимо проанализировать словарные статьи на русском языке, чтобы определить, являются указанные лексемы эквивалентами.

Так, согласно «Полному словарю лингвистических терминов» под редакцией Т.В. Матвеевой, «синтагма - речевое звено, часть линейного речевого ряда, элементы которого связаны отношениями синтагматики, т.е. смежности, сочетаемости, следования. Это относительно целостная в смысловом и, что особенно важно, в ритмикомелодическом отношении единица речи. С фонетико-интонационной точки зрения, синтагма, или речевой такт, - это смысловая и рит- 
мико-интонационная группа фонем, выступающая единицей фонетического членения речевого потока. Синтагма создается единым ударением, общим интонационным рисунком, начальной и конечными паузами. В отличие от фразы, синтагма интонационной законченностью не обладает [6, с. 412-413].

Сходное определение термина «синтагма», употребляемого в сфере фонетики, находим в «Словаре лингвистических терминов» О.С. Ахмановой:

Синтагма - то же, что речевое звено (речевой такт, ритмико-интонационная группа, синтагма) - кратчайшая знаменательная часть фразы, выделяемая ритмико-интонационными средствами [1, с. 385, 408].

Таким образом, на основе анализа дефиниций терминов «синтагма» и 'intonational phrase' можно сделать вывод, что данные терминологические единицы не являются эквивалентами, поэтому использование лексемы «синтагма» при переводе специальных текстов может вызвать непонимание специалистов. Приведенные выше определения из русскоязычных лексикографических источников свидетельствуют о совпадении семантических структур терминов «фраза» и 'intonational phrase' [1, с. 502]. Таким образом, можно утверждать, что для обозначения основной единицы интонационной структуры, характеризующейся изменением тона, в русской фонетической традиции используется термин «фраза», который может заменяться в рамках межъязыкового общения англоязычными терминологическими единицами: 'intonational phrase', 'tone unit', 'tone group', 'intonation group'.

Проведенный анализ семантики приведенных синонимичных единиц, служащих для вербализации единицы интонации, показал, что специальная лексическая единица 'intonation group' практически не употребляется на современном этапе и может считаться устаревшей. Термины 'tone unit' и 'tone group', согласно статистическим данным, применяются специалистами приблизительно в равной пропорции, при этом в Британском корпусе текстов лексема 'tone group' демонстрирует несколько большую частотность. Наиболее востребованной в современных фонетических исследованиях является терминологическая единица 'intonational phrase', как в Британском, так и Американском корпусе, однако в последнем превалирование данной лексемы в профессиональном дискурсе является более явным.

\section{ЛИТЕРАТУРА}

1. Ахманова 0.С. Словарь лингвистических терминов. - M.: URSS, 2020. - 576 с.

2. Гвишиани Н.Б. Язык научного общения. Вопросы методологии. - М.: Издательство ЛКИ, 2017. - 280 с.

3. Гринев С.В. Сопоставительное терминоведение: современное состояние // Вестник Московского городского педагогического университета. Серия: «Филология. Теория языка. Языковое образование». - 2017. - № 1 (25). - С. 68-75.

4. Гринев-Гриневич С.В. Терминоведение. - М.: Академия, 2008. - 304 с.

5. Лейчик В.М. Терминоведение: предмет, методы, структура. - М.: Либроком, 2019. - 264 с.

6. Матвеева Т.В. Полный словарь лингвистических терминов. - Ростов-н/Д: Феникс, 2010. - 562 с.

7. Суперанская А.В., Подольская Н.В., Васильева Н.В. Общая терминология: Вопросы теории. - М.: Либроком, 2012. - 248 с.

8. Суперанская А.В., Подольская Н.В., Васильева Н.В. Общая терминология: Терминологическая деятельность. - М.: Издательство ЛКИ, 2014. - 288 с.

9. Crystal, D. A Dictionary of Linguistics and Phonetics. - 6th ed. - Oxford: Blackwell Publishing, 2008 - $529 \mathrm{p}$.

10. Roach P. A Little Encyclopedia of Phonetics. - Cambridge: Cambridge University Press, 2002. - 93 p.

11. Trask, R.L. Dictionary of Phonetics and Phonology. - London, New York: Routledge, 2005. - 424 p. 